\title{
PERANCANGAN SISTEM PENGENDALIAN MENGGUNAKAN KONTROLER PID PADA GERAKAN PITCH DAN ROLL UNTUK STABILITAS ATTITUDE HEXACOPTER
}

\author{
Achmad Ryan Perdana \\ Jurusan Teknologi Industri dan Proses \\ Program Studi Teknik Mesin \\ Institut Teknologi Kalimantan \\ Email: $\underline{\text { 03161004@ student.itk.ac.id }}$ \\ Illa Rizianiza \\ Jurusan Teknologi Industri dan Proses \\ Program Studi Teknik Mesin \\ Institut Teknologi Kalimantan \\ Email: rizianiza@lecturer.itk.ac.id
}

\begin{abstract}
ABSTRAK
Drone Hexacopter merupakan salah satu jenis UAV tipe rotary wing. Hexacopter memiliki 6 buah motor penggerak, biasa disebut multirotor. Drone Hexacopter memiliki sistem yang kompleks dan nonlinear. Sifat sistem hexacopter menyebabkan proses pengendalian sulit dilakukan saat sistem kontrol tidak dirancang dengan baik sehingga menjadi tantangan untuk penelitian mendatang. Dibutuhkan perancangan sistem kontrol hexacopter yang dapat menjaga kestabilan gerak attitude saat drone berada di udara yaitu variabel pitch dan roll. Tujuan dari penelitian ini ialah menentukan parameter PID untuk gerakan pitch dan roll pada hexacopter. Penelitian ini, pemodelan sistem untuk mendapatkan transfer function dilakukan dengan engineering tools black-box modeling yaitu Autoreggresive Moving Average eXogenous (ARMAX). Metode ini menggunakan data input dan output drone berupa sudut perintah dan sudut aktual (pitch dan roll). Perancangan kontroler dilakukan dengan mencari parameter PID lalu dilakukan simulasi menggunakan software komputer. Hasil setelah perancangan diharapkan mengalami improvisasi atau lebih baik dari sistem sebelumnya setelah dilakukan simulasi.
\end{abstract}

Kata kunci: ARMAX, attitude, hexacopter, PID

\begin{abstract}
Hexacopter drone are one type of the UAV of rotary wing type. Hexacopter has 6 motors, commonly called multirotor. Hexacopter system is nonlinear and complex. The dynamic nature of the hexacopter makes it difficult to control the process when the control system is not well designed so it is a challenge for future research. A hexacopter control system is needed which can maintain the stability of the attitude when the drone is in the air that is pitch and roll variable. So, the aim of this research is to determine the PID parameters for pitch and roll movements on hexacopter. In this research, the system modeling process to get the transfer function is done with engineering tools black-box modeling namely Autoreggresive Moving Average eXogenous (ARMAX). This method uses drone input and output data in the form of desired angles and actual angles (pitch and roll). The design of the controller is done by finding the PID parameters and then simulating using computer software. The results after the design are expected to experience improvisation or better than the previous system after the simulation.
\end{abstract}

Keywords: ARMAX, attitude, hexacopter, PID 


\section{PENDAHULUAN}

Perkembangan teknologi saat ini bertumbuh dengan berbagai macam bentuk teknologi automasi. Salah satunya bidang aviasi yaitu pesawat udara tanpa awak atau biasa disebut dengan singkatan Unmanned Aerial Vehicle (UAV), UAV merupakan sebuah robot terbang yang dapat dioperasikan dengan/tanpa pilot. Perkembangan teknologi UAV saat ini sangat pesat dan terintegrasi seiring berkembangnya ilmu pengetahuan dalam bidang kedirgantaraan. UAV dapat dikendalikan secara manual maupun autonomous (dengan komputer) [2].

Ada beberapa jenis dan tipe dari UAV yang secara umum terbagi menjadi dua yaitu multirotor dan fixed wing. Jenis multirotor dibedakan berdasarkan jumlah motor yang terdapat pada drone tersebut. Penggunaan quadcopter atau empat motor sangat populer dan merupakan jenis yang umum digunakan dalam penelitian di dalam maupun di luar ruangan. Saat ini secara luas perkembangan multirotor menggunakan lebih dari empat motor sedang banyak dilakukan salah satunya adalah hexacopter yang menggunakan enam motor. Hexacopter memiliki beberapa keunggulan dibanding quadcopter yaitu daya tahan (endurance) terbang lebih lama dan dapat mengangkat pay-load yang lebih besar karena memiliki jumlah motor yang lebih banyak [7].

Hexacopter merupakan sistem yang nonlinear, multivariabel dan dinamis sehingga perancangan sistem kendali serta kestabilannya akan menjadi tantangan dan fokus penelitian utama pada perkembangan hexacopter [3].

Beberapa penelitan sebelumnya telah dilakukan perancangan Proportional-IntegralDerivative (PID) untuk menjaga attitude pada UAV, diterapkan pada multicopter jenis quadcopter dan kebanyakan pemodelan UAV dilakukan menggunakan pemodelan fisika. Hasil yang ditunjukkan adalah permasalahan osilasi berlebih pada respon sistem sehingga mempengaruhi stabilitas hexacopter ketika melakukan gerak translasi. Salah satu kriteria sebuah kontrol stabilitas dikatakan baik ialah quick response, jika terjadi rapid response maka itu adalah penyebab osilasi berlebih pada respon sistem dan osilasi adalah permasalahan pada stabilitas hexacopter [6].

Penelitian tentang pemodelan salah satunya adalah metode black-box modeling dimana terdapat sebuah pemodelan Autoreggresive Moving Average Exogeous (ARMAX). Keunggulan dari pemodelan ARMAX adalah hasil data yang didapatkan untuk pemodelan sistem memiliki nilai fitness/kecocokan yang besar terhadap sistem aktualnya [8]

Perancangan sistem pengendalian stabilitas attitude hexacopter meliputi dua aspek utama yaitu desain PID dan identifikasi model. Identifikasi model sistem dilakukan menggunakan metode Autoregressive Moving Average eXogenous (ARMAX). Penelitian ini dilakukan untuk mendapatkan dan menganalisis hasil respon sistem menggunakan metode kontrol PID dengan judul Perancangan Sistem Pengendalian Menggunakan Kontroler PID (Proportional-Integral-Derivative) pada Gerakan Pitch dan Roll untuk Stabilitas Attitude Hexacopter.

\section{METODOLOGI PENELITIAN}

Penelitian ini merupakan hasil dari studi kasus Asmawarman Team yaitu salah satu penggiat pengembangan UAV di Kalimantan. Hasil perancangan drone hexacopter dalam Kontes Robot Tebang Indonesia (KRTI) tahun 2019. Berikut beberapa tahapan yang dilakukan dalam penelitian ini:

\subsection{Studi Literatur}

Tahap ini dilakukan proses pencarian serta pengkajian literatur baik berupa hasil penelitian maupun buku yang berkaitan guna membantu penyelesaian penelitian tugas akhir. Proses studi literatur menitik beratkan pencarian dan pengkajian pada materi seputar drone hexacopter [8], Proportional-Integral-Derivative (PID), Black-Box Modeling Autoregressive Moving Average Exogenous (ARMAX) [4], Mission Planner (MP) [1], dan Metode Ziegler-Nichols [10] serta Respon Sistem. 


\subsection{Perancangan Alat}

Tahap ini dilakukan proses perancangan drone hexacopter. Pembuatan hexacopter dimulai dengan perancangan frame kemudian pemilihan komponen-komponen pendukung dari sistem maupun elektrik. Perancangan drone sepenuhnya dilakukan oleh team.

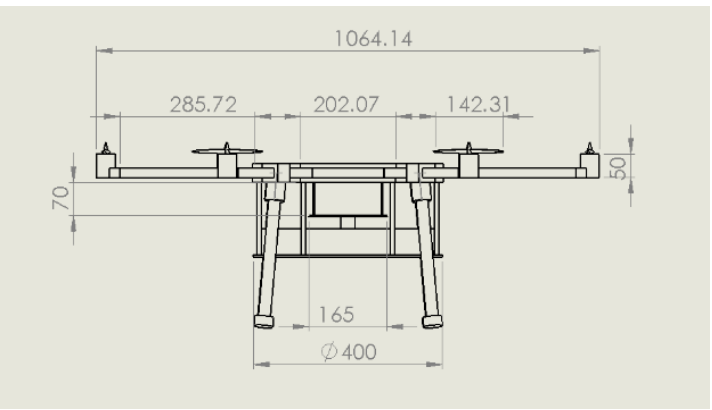

Gambar 1. Desain dan Dimensi Tampak Depan

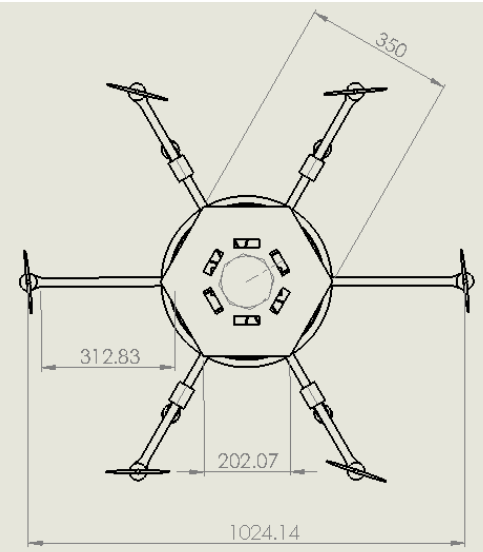

Gambar 2. Desain dan Dimensi Tampak Atas

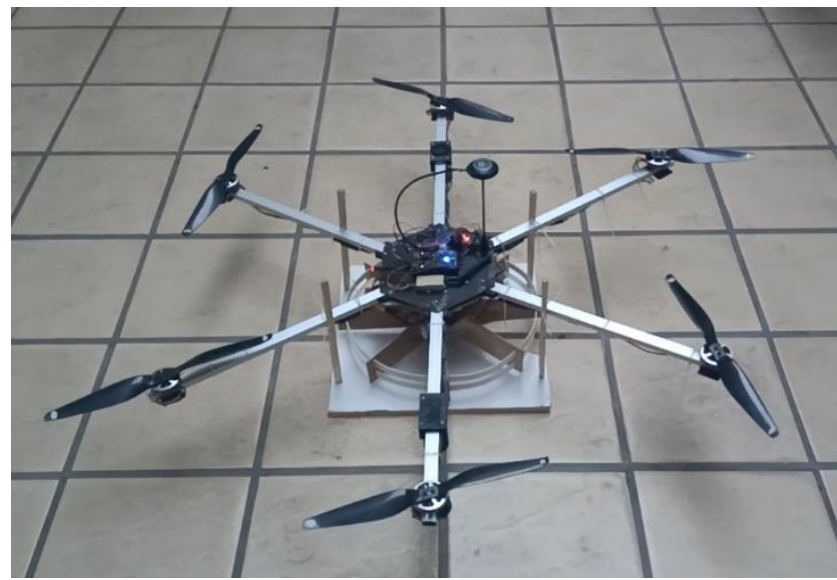

Gambar 3. Prototype Drone Hexacopter 


\subsection{Pengambilan Data}

Data drone hexacopter berupa sudut perintah drone (pitch dan roll) dan sudut aktual (pitch dan roll) drone dengan melakukan uji terbang. Uji terbang menggunakan remote control dalam flight mode autonomous untuk mempertahankan ketinggian agar menghindari human error selama terbang. Selanjutnya mengunduh data dari flight controller ke laptop dengan aplikasi Mission Planner (GCS). Data berupa nilai Pulse Width Modulation (PWM) pada sudut pitch dan roll. Data tersebut direkam oleh sistem black-box pada flight controller pixhawks selama drone terbang.

\subsection{Pemodelan Sistem}

Pemodelan sistem adalah tahapan dalam melakukan perancangan sistem, meliputi 3 tahap yaitu identifikasi sistem hexacopter lalu pemodelan sistem black-box ARMAX [4]. Setelah pemodelan dilakukan perancangan kontroler PID menggunakan metode Ziegler-Nichols [10]. Gambar 3 menunjukan proses coding pada tahap pemodelan sistem black-box ARMAX dan hasil yang didapatkan ialah transfer fungsi dari tiap gerakan serta nilai fit/kecocokan hasil estimasi software terhadap data yang diperoleh. Line coding tidak ditampilkan seutuhnya untuk privasi penelitian.

\subsection{Simulasi}

Tahap simulasi adalah proses pengujian kontroler PID yang telah dibuat. Pengujian dilakukan secara simulasi menggunakan software. Simulasi dikatakan sesuai jika menunjukan hasil maksimal pada salah satu penggunaan kontroler P, PI, maupun PID.

\subsection{Analisis dan Pembahasan}

Analisis dan pembahasan dilakukan setelah mendapat hasil dari simulasi sistem default. Analisis yang dilakukan adalah analisis respon guna mencari parameter PID terbaru terhadap PID default. Analisis dilakukan dengan melihat nilai parameter PID rancangan [9].

\section{HASIL DAN PEMBAHASAN}

Berikut hasil dan analisis pembahasan pada penelitian Perancangan Sistem Pengendalian Menggunakan Kontroler PID pada Gerakan Pitch dan Roll untuk Stabilitas Attitude Hexacopter.

\subsection{Hasil Pengambilan Data}

Proses pengambilan data dilakukan secara langsung dengan menerbangkan hexacopter dan melakukan gerak attitude khususnya gerakan roll dan pitch. Proses perekaman data dilakukan secara real-time oleh flight controller kemudian ditransmisikan menggunakan telemetry ke laptop. Ketelitian perolehan data ialah 1 data per 1/10 detik. Sehingga 1 detik didapatkan 10 data. Total data yang diperoleh ialah 79076 data gerak attitude. Data yang diperoleh berupa sudut perintah sebagai input dan sudut aktual sebagai output, kemudian data diolah menggunakan excel, berikut Tabel 1:

Tabel 1. Hasil Pengambilan Data

\begin{tabular}{ccccccc}
\hline & \multicolumn{2}{c}{ ROLL } & \multicolumn{2}{c}{ PITCH } & \multicolumn{2}{c}{ YAW } \\
\hline No & Desired $\left({ }^{0}\right)$ & Aktual $\left({ }^{0}\right)$ & Desired $\left({ }^{0}\right)$ & Aktual $\left({ }^{0}\right)$ & Desired $\left({ }^{0}\right)$ & Aktual $\left({ }^{0}\right)$ \\
\hline 1 & $-0,53$ & $-0,53$ & 2,24 & 2,24 & 266,25 & 266,26 \\
2 & $-0,52$ & $-0,52$ & 2,24 & 2,24 & 266,25 & 266,26 \\
3 & $-0,52$ & $-0,52$ & 2,25 & 2,25 & 266,25 & 266,26 \\
\hline
\end{tabular}




\begin{tabular}{ccccccc}
\hline & \multicolumn{2}{c}{ ROLL } & \multicolumn{2}{c}{ PITCH } & \multicolumn{2}{c}{ YAW } \\
\hline No & Desired $\left({ }^{0}\right)$ & Aktual $\left({ }^{0}\right)$ & Desired $\left({ }^{0}\right)$ & Aktual $\left({ }^{0}\right)$ & Desired $\left(^{0}\right)$ & Aktual $\left({ }^{0}\right)$ \\
\hline 4 & $-0,52$ & $-0,52$ & 2,25 & 2,25 & 266,25 & 266,26 \\
5 & $-0,52$ & $-0,52$ & 2,25 & 2,25 & 266,25 & 266,26 \\
- & - & - & - & - & - & - \\
79073 & $-1,62$ & $-0,91$ & 0,39 & 1,25 & 279,53 & 275,64 \\
79074 & $-1,62$ & $-0,92$ & 0,4 & 1,25 & 279,53 & 275,64 \\
79075 & $-1,62$ & $-0,92$ & 0,41 & 1,24 & 279,53 & 275,64 \\
79076 & $-1,63$ & $-0,92$ & 0,41 & 1,24 & 279,53 & 275,65 \\
\hline
\end{tabular}

Gambar 4 dan Gambar 5 menunjukan grafik hasil pengambilan data gerakan pitch dan roll. Trend dengan grafik signifikan menunjukan waktu pengambilan data gerakan tersebut.

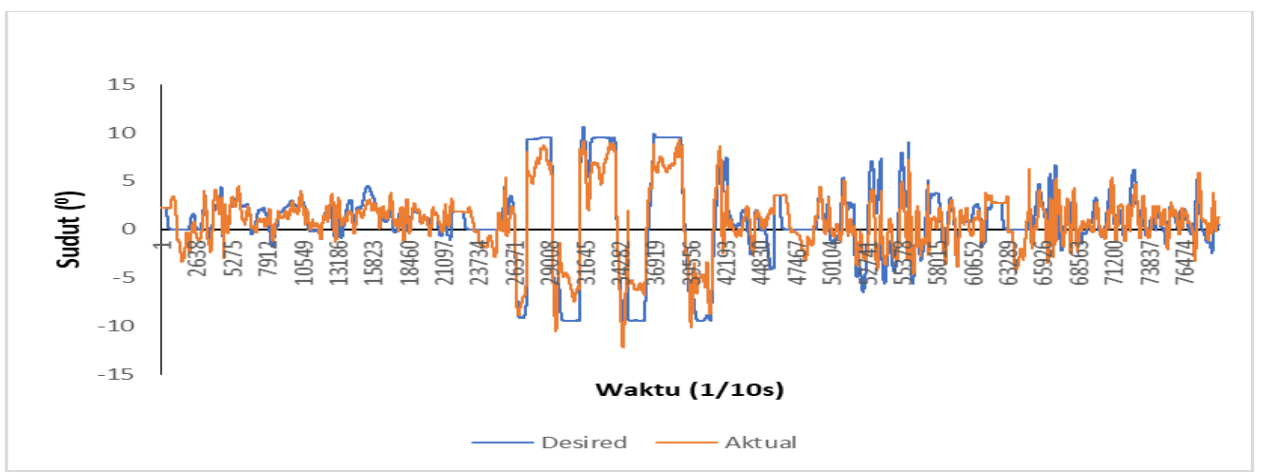

Gambar 4. Grafik Data Gerakan Pitch

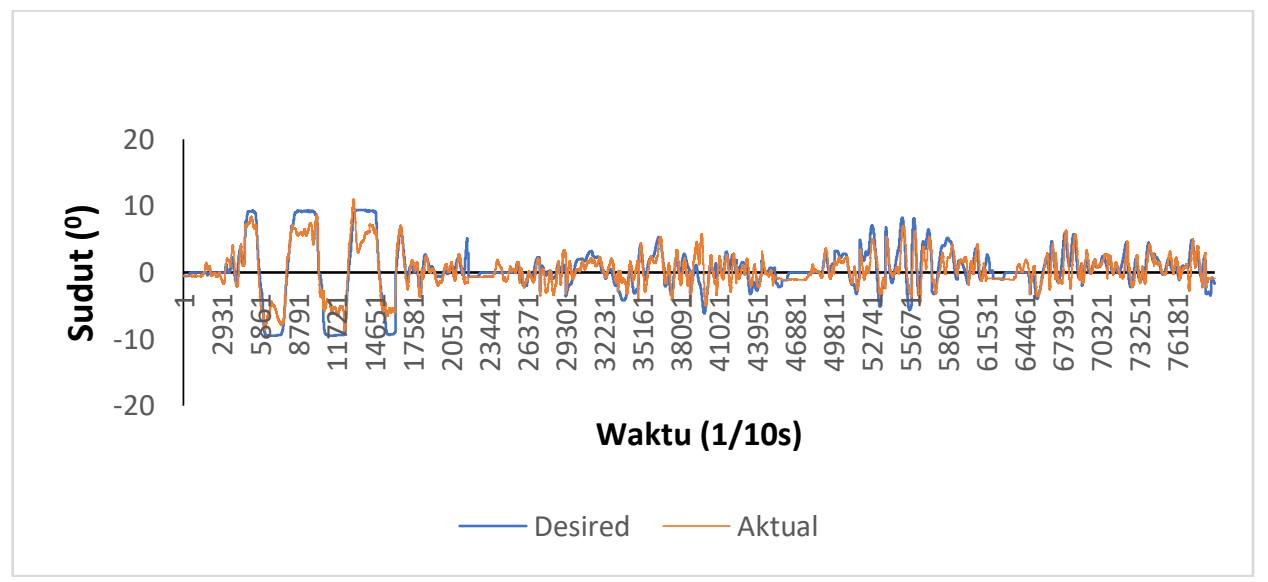

\section{Gambar 5. Grafik Data Gerakan Roll}

Data yang berjumlah 79076 itu kemudian dipisahkan dan dipilih sesuai waktu pengambilan data gerakan. Blue line merupakan sudut yang diinginkan dan orange line merupakan sudut aktual dari hexacopter. Hasil pemisahan grafik data ini selanjutnya akan digunakan untuk melakukan pemodelan sistem dan simulasi untuk mendapatkan parameter PID terbaru. Berikut Gambar 6 dan Gambar 7 menunjukan grafik data gerakan: 


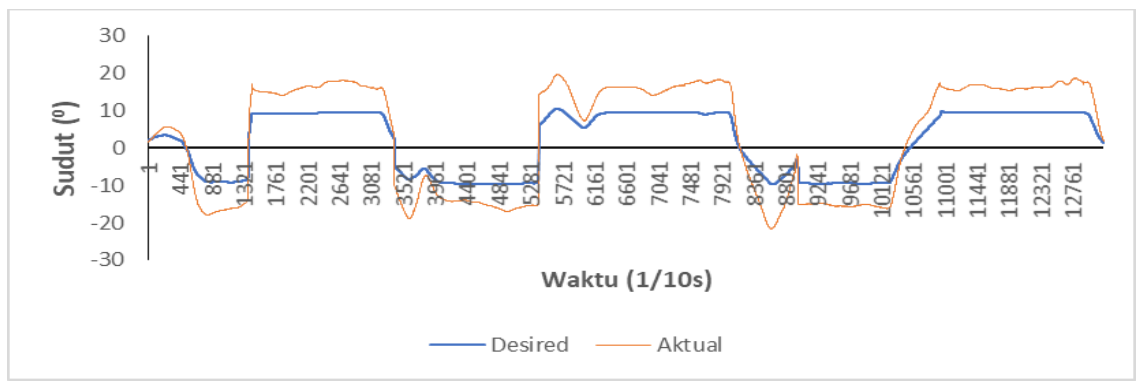

Gambar 6. Grafik Data Pitch

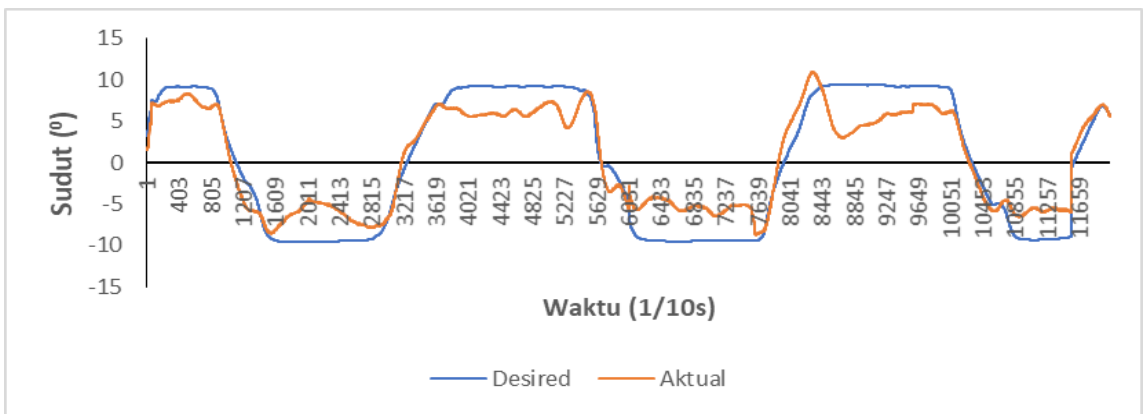

Gambar 7. Grafik Data Roll

\subsection{Pemodelan Sistem}

Hasil pemodelan sistem yang didapatkan setelah proses coding menggunakan engineering tools ARMAX menunjukan nilai transfer fungsi gerakan pitch dan roll dan nilai fit/kecocokan pemodelan terhadap data sesungguhnya sebagai validasi. Berikut hasilnya:

\subsubsection{Pemodelan Sistem Gerakan Pitch}

ARMAX:

Berikut hasil pemodelan sistem untuk gerakan pitch menggunakan engineering tools

Continuous-time ARMAX model: $\mathrm{A}(\mathrm{s}) \mathrm{y}(\mathrm{t})=\mathrm{B}(\mathrm{s}) \mathrm{u}(\mathrm{t})+\mathrm{C}(\mathrm{s}) \mathrm{e}(\mathrm{t})$

$$
\begin{aligned}
& A(s)=s^{3}+6,365 s^{2}+9,111 s+0,2635 \\
& B(s)=0,8843 s^{2}+7,556 s+0,1826 \\
& C(s)=s^{3}+17,07 s^{2}+56,71 s+82,92
\end{aligned}
$$

Transfer Fungsi Pitch $=$

$$
\frac{0,8843 s^{2}+7,556 s+0,1826}{s^{3}+6,365 s^{2}+9,111 s+0,2635}
$$

Transfer fungsi (TF) untuk gerakan pitch telah didapatkan, TF berbentuk fungsi laplace agar dapat meramal respon sistem sampai waktu tak hingga. TF berorde tinggi yaitu ditunjukan dari nilai s berpangkat lebih dari 2, hal ini disebabkan sifat hexacopter yang non-liner, multivariable dan dinamis. Setelah TF didapat, kemudian hasil fit pemodelan dilihat untuk menentukan apakah model sistem yang dihasilkan dapat digunakan untuk merancang kontroler PID terbaru. Gambar 8 menunjukan nilai fit: 


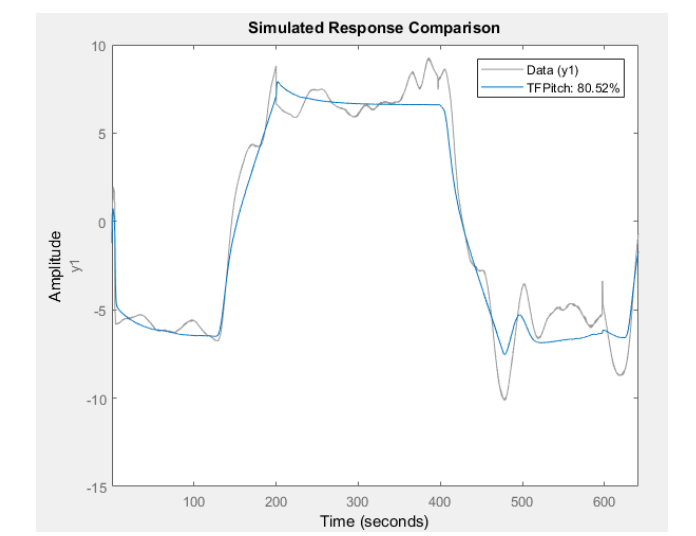

Gambar 8. Grafik Nilai Fit Sistem Gerakan Pitch

Gambar 8 menunjukan nilai fit/kecocokan pemodelan terhadap data percobaan dimana nilai fit sebesar 80,52\%. Grey line adalah data pitch pada Gambar 6 dan blue line adalah Nilai TF hasil simulasi. Hasil nilai fit dari model sistem gerakan pitch baik untuk melakukan desain kontroler PID ketahap selanjutnya [9].

\subsubsection{Pemodelan Sistem Gerakan Roll} ARMAX:

Berikut hasil pemodelan sistem untuk gerakan pitch menggunakan engineering tools Continuous-time ARMAX model: $\mathrm{A}(\mathrm{s}) \mathrm{y}(\mathrm{t})=\mathrm{B}(\mathrm{s}) \mathrm{u}(\mathrm{t})+\mathrm{C}(\mathrm{s}) \mathrm{e}(\mathrm{t})$

$$
\begin{aligned}
& A(s)=s^{3}+29,93 s^{2}+9,311 s+0,3051 \\
& B(s)=-18,46 s^{2}+9,792 s+0,2267 \\
& C(s)=s^{3}+47,28 s^{2}+339,5 s+127,3
\end{aligned}
$$

Transfer Fungsi Roll $=$

$$
\frac{-18,46 s^{2}+9,792 s+0,2267}{s^{3}+29,93 s^{2}+9,311 s+0,3051}
$$

Transfer fungsi (TF) untuk gerakan roll telah didapatkan, hasil yang didapat sama halnya dengan gerakan pitch. TF berorde tinggi yaitu ditunjukan dari nilai $\mathbf{s}$ berpangkat lebih dari 2 , hal ini disebabkan sifat hexacopter yang non-liner, multivariable dan dinamis. Setelah TF didapat, kemudian hasil fit pemodelan dilihat untuk menentukan apakah model sistem yang dihasilkan dapat digunakan untuk merancang kontroler PID terbaru. Gambar 9 menunjukan nilai fit:

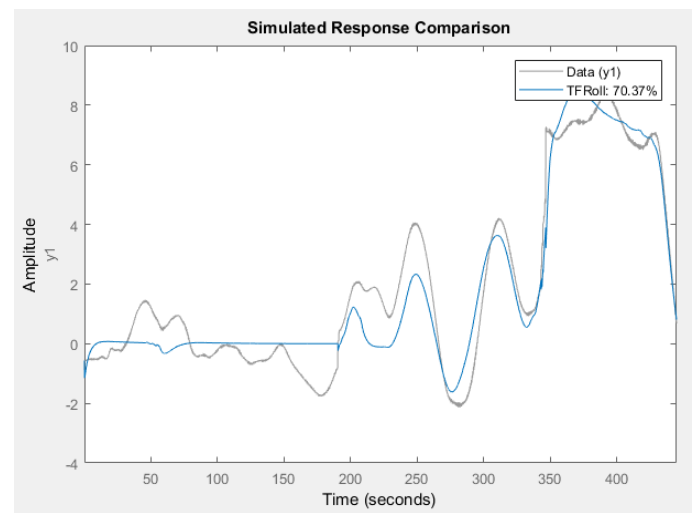

Gambar 9. Grafik Nilai Fit Sistem Gerakan Roll 
Sama halnya dengan gerakan pitch. Gambar 9 menunjukan nilai fit pemodelan sistem terhadap data percobaan dimana nilai fit sebesar 70,37\%. Grey line adalah data roll pada Gambar 7 dan blue line adalah Nilai TF hasil simulasi. Hasil nilai fit dari model sistem gerakan pitch baik untuk melakukan desain kontroler PID ketahap selanjutnya berdasar penelitian terdahulu [9].

\subsection{Simulasi Model Sistem Gerakan Pitch}

Simulasi ini menggunakan sistem open loop. ARMAX sudah mewakili keseluruhan sistem gerakan pitch hexacopter yang sebenarnya memiliki sistem close loop. Transfer function yang telah didapatkan dari hasil simulasi coding digunakan dalam simulasi sistem. Berikut Gambar 10 menunjukan diagram blok simulasi dan Gambar 11 menunjukan hasil respon sistem pitch:

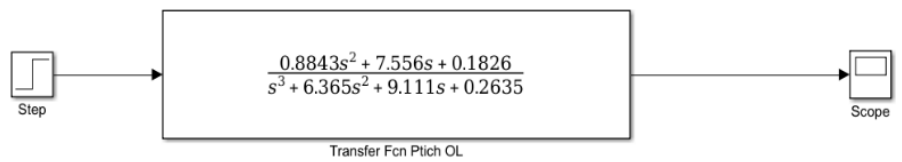

Gambar 10. Diagram Blok Gerakan Pitch

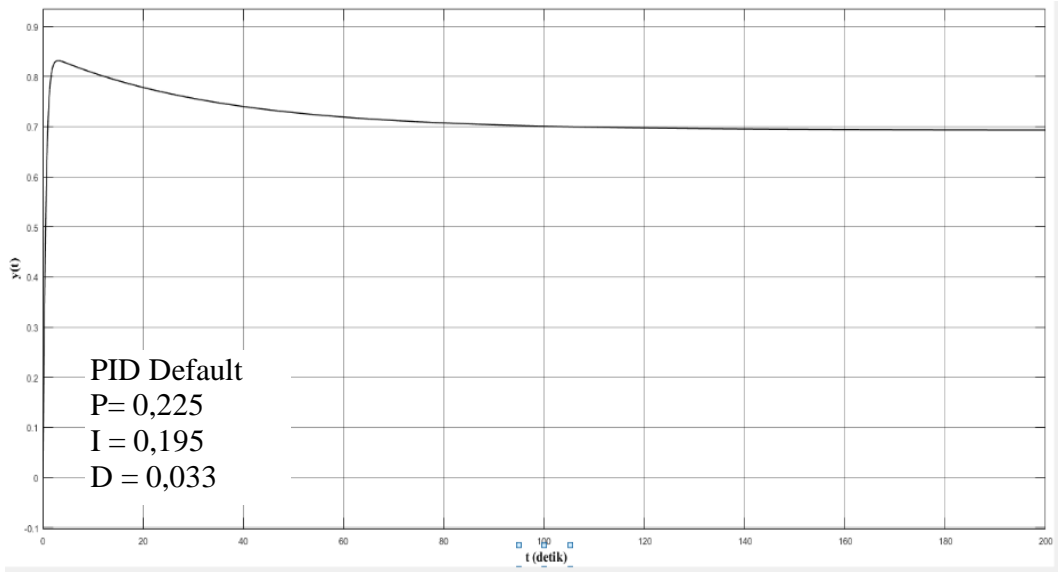

Gambar 11. Respon Sistem Gerakan Pitch

Simulasi respon sistem dilakukan selama 200 detik. Grafik respon sistem tidak sampai pada set point yaitu 1 tetapi hanya sampai 0,6944 walaupun rise-time sistem cukup baik. Waktu yang dibutuhkan sistem agar stabil cukup lama untuk sampai pada titik 0,6944 yaitu lebih dari 140 detik. Respon sistem yang dihasilkan memiliki nilai antara lain:

1. Nilai Overshoot sebesar $19,880 \%$

2. Nilai Rise-Time sebesar 0,728 detik

3. Nilai Settling Time sebesar 0 detik karena tidak mencapai set point

Hasil respon sistem PID default memiliki overshoot yang cukup besar, akibatnya ialah terjadi osilasi sebesar nilai overshoot setelah melakukan gerakan pitch yang dapat berakibat fatal. Rise-time yang dihasilkan sangat cepat sehingga perubahan sudut drone ketika melakukan gerakan menjadi sangat cepat, akibatnya berpengaruh pada peningkatan nilai overshoot. Selanjutanya nilai akhir sistem tidak mencapai set point. Hasil respon sistem ini tidak optimal dan belum dapat membuat sistem untuk gerakan pitch stabil.

Hasil di atas merupakan nilai dari respon sistem untuk gerakan pitch menggunakan PID default/belum dilakukan perancangan kontroler PID baru. 


\subsection{Simulasi Model Sistem Gerakan Roll}

Simulasi ini sama halnya dengan gerakan pitch yaitu menggunakan sistem open loop. transfer fungsi dari gerakan roll yang didapat menggunakan ARMAX sudah mewakili keseluruhan sistem hexacopter untuk gerak roll, dimana sistemnya berbentuk close loop. Berikut Gambar 12 menunjukan diagram blok simulasi dan Gambar 13 menunjukan hasil respon sistem roll:

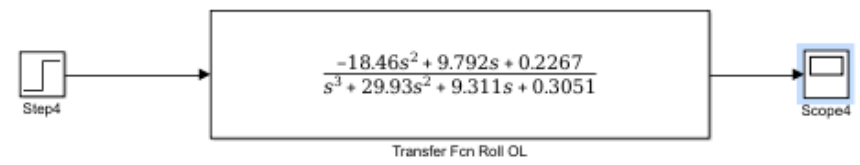

Gambar 12. Diagram Blok Gerakan Roll

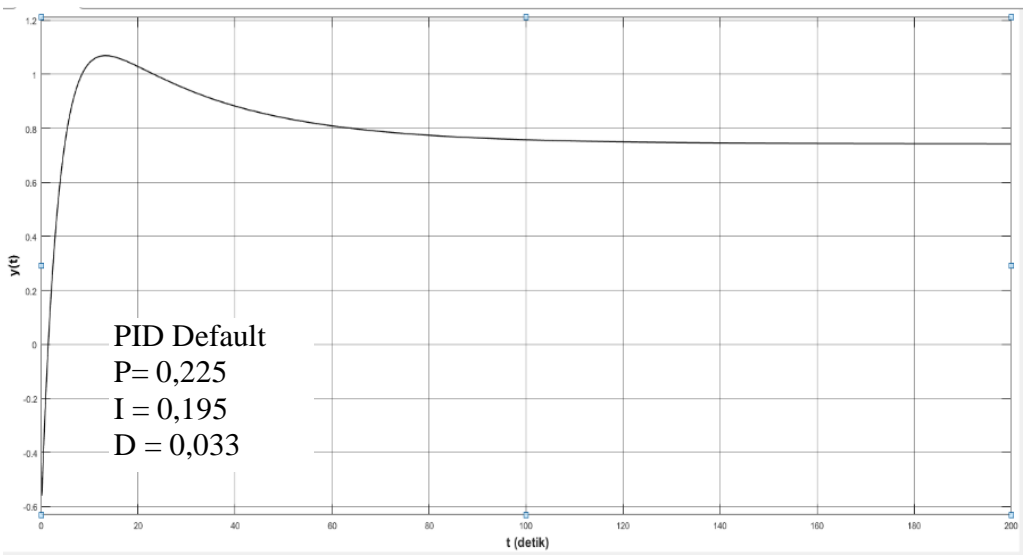

Gambar 13. Respon Sistem Gerakan Roll

Simulasi respon sistem dilakukan selama 200 detik. Grafik respon sistem tidak sampai pada set point yaitu 1 tetapi hanya sampai 0,7519 walaupun overshoot sempat melewati set point. Kemudian waktu yang dibutuhkan sistem untuk stabil cukup lama agar sampai pada titik 0,7519 (titik stabil) yaitu lebih dari 100 detik. Hal ini disebabkan tidak maksimalnya kontroler PID untuk gerakan roll. Respon sistem yang dihasilkan memiliki nilai antara lain ialah:

1. Nilai Overshoot sebesar $24,375 \%$

2. Nilai Rise-Time sebesar 3,608 detik

3. Nilai Settling Time sebesar 0 detik karena tidak mencapai set point

Hasil respon sistem PID default memiliki overshoot yang cukup besar, akibatnya ialah terjadi osilasi sebesar nilai overshoot setelah melakukan gerakan pitch yang dapat berakibat fatal, salah satu penyebabnya juga karena gerakan roll menggunakan 3 motor untuk melakukan translasi sedangkan gerakan pitch menggunakan 2 motor. Rise-time yang cukup besar mempengaruhi kecepatan perubahan sudut drone ketika akan melakukan gerakan, akibatnya drone kurang tangkas dalam bergerak. Kemudian sama halnya dengan pitch, nilai akhir tidak mencapai set point. Sistem menggunakan PID default belum optimal dalam menjaga stabilitas gerakan Hexacopter.

Hasil di atas merupakan nilai dari respon sistem gerakan roll menggunakan PID default/belum dilakukan perancangan kontroler PID baru. Tahap selanjutnya adalah Perancangan Kontroler PID menggunakan metode Ziegler-Nichols (ZN) pada hasil tiap respon sistem gerak attitude.

\subsection{Perancangan Kontroler PID dan Analisis}

Perancangan kontroler PID untuk gerakan pitch dan roll mengacu pada grafik respon sistem berturut-turut pada Gambar 11 dan Gambar 13. Metode perancangan kontroler PID baru ialah Ziegler-Nichols tipe 1 karena grafik respon sistem kedua gerakan berbentuk kurva tangensial. Grafik 
respon sistem yang dihasilkan setiap gerakan kemudian dilakukan pencarian nilai $\mathrm{L}$ dan $\mathrm{T}$ dengan metode ZN tipe 1 seperti pada Gambar 14:

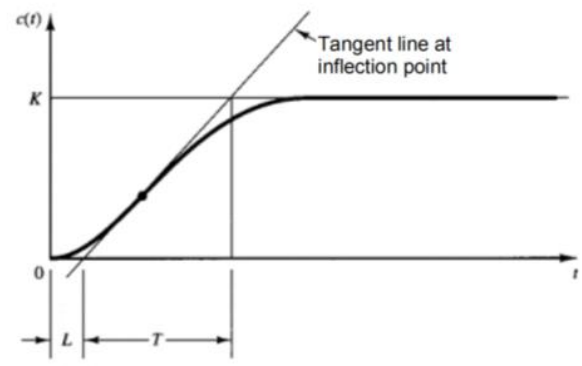

Gambar 14. Perolehan Parameter/Nilai L dan T pada Kurva

\subsubsection{Perancangan dan Analisis Kontroler Pitch}

\section{Sumber: Modern Control Engineering [5]}

Berikut nilai $\mathrm{T}$ dan $\mathrm{L}$ yang diperoleh dari hasil respon sistem default gerakan pitch:

$$
\begin{aligned}
\mathbf{T} & =\mathbf{0 , 5 4 8} \\
\mathbf{L} & =\mathbf{0 , 2 8}
\end{aligned}
$$

Hasil nilai $\mathrm{T}$ dan $\mathrm{L}$ yang telah didapat kemudian digunakan untuk mencari parameter kontroler PID gerakan pitch mengacu persamaan rumus pada Tabel 2 berikut:

Tabel 2. Rumus Parameter Metode ZN Tipe 1

\begin{tabular}{crcc}
\hline Tipe Kontroler & $\mathrm{K}_{\mathrm{p}}$ & $\tau_{\mathrm{i}}$ & $\tau_{\mathrm{d}}$ \\
\hline $\mathrm{P}$ & $\frac{\mathrm{T}}{\mathrm{L}}$ & $\infty$ & 0 \\
PI & $0,9 \frac{T}{L}$ & $\frac{T}{0,3 L}$ & 0 \\
PID & $1,2 \frac{T}{L}$ & $2 \mathrm{~L}$ & $0,5 \mathrm{~L}$ \\
\hline
\end{tabular}

Sumber: Modern Control Engineering [5]

Nilai parameter diperoleh setelah dilakukan perhitungan menggunakan nilai $\mathrm{T}$ dan $\mathrm{L}$ seperti pada Tabel 2 dan menunjukan hasil yang maksimal pada penggunaan kontroler PI dibanding menggunakan kontroler $\mathrm{P}$ dan PID. Berikut nilai parameter $\mathrm{K}_{\mathrm{p}}$ dan $\tau_{\mathrm{i}}$ yang didapat:

$$
\begin{array}{cc}
\mathbf{K}_{\mathbf{p}} & =\mathbf{1 , 7 6 2} \\
\tau_{\mathrm{i}} & =\mathbf{0 , 9 3 3}
\end{array}
$$

Nilai parameter yang dihasilkan untuk gerakan pitch menunjukan perbedaan yang signifikan dibanding PID default Hasil pemodelan sistem dengan kontroler PID rancangan ini selanjutnya dapat disimulasikan dan dilihat perbandingan respon sistem sebelum dan sesudah perancangan kontroler. Pemodelan sistem kontroler rancangan untuk gerakan pitch ditunjukan oleh gambar Gambar 15: 


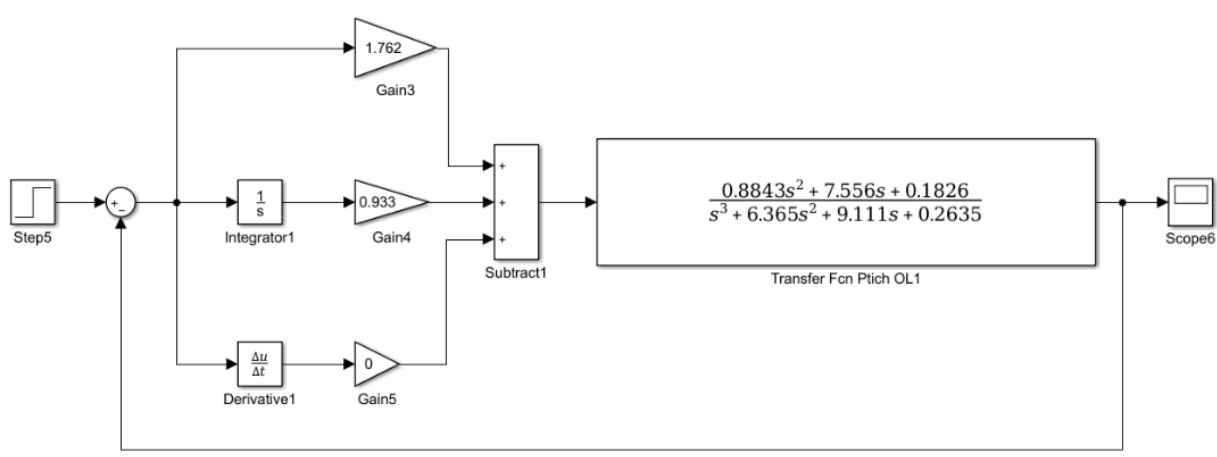

Gambar 15. Diagram Blok Pemodelan Sistem Pitch

\subsubsection{Perancangan dan Analisis Kontroler Roll}

Berikut nilai $\mathrm{T}$ dan $\mathrm{L}$ yang didapatkan dari hasil respon sistem gerakan roll:

$$
\begin{aligned}
\mathbf{T} & =\mathbf{0 , 2 6} \\
\mathbf{L} & =\mathbf{0 , 1 9 3}
\end{aligned}
$$

Hasil nilai $\mathrm{T}$ dan $\mathrm{L}$ yang telah didapat, digunakan untuk mencari parameter kontroler PID untuk gerakan roll mengacu persamaan rumus pada Tabel 2 diatas. Nilai parameter setelah dilakukan perhitungan nilai $\mathrm{T}$ dan $\mathrm{L}$ menunjukan hasil yang maksimal pada penggunaan kontroler PI dibanding menggunakan kontroler $P$ dan PID. Berikut nilai parameter $K_{p}$ dan $\tau_{i}$ yang didapat:

$$
\begin{aligned}
\mathbf{K}_{\mathbf{p}} & =\mathbf{1 , 2 1 6 5} \\
\tau_{\mathrm{i}} & =\mathbf{0 , 6 4 3}
\end{aligned}
$$

Nilai parameter yang dihasilkan untuk gerakan roll menunjukan perbedaan yang cukup signifikan dibanding PID default. Hasil Pemodelan sistem gerakan roll ini selanjutnya dapat disimulasikan untuk melihat perbandingan respon sistem sebelum dan sesudah perancangan kontroler. Gambar 16 menunjukan diagram blok pemodelan sistem dengan kontroler rancangan:

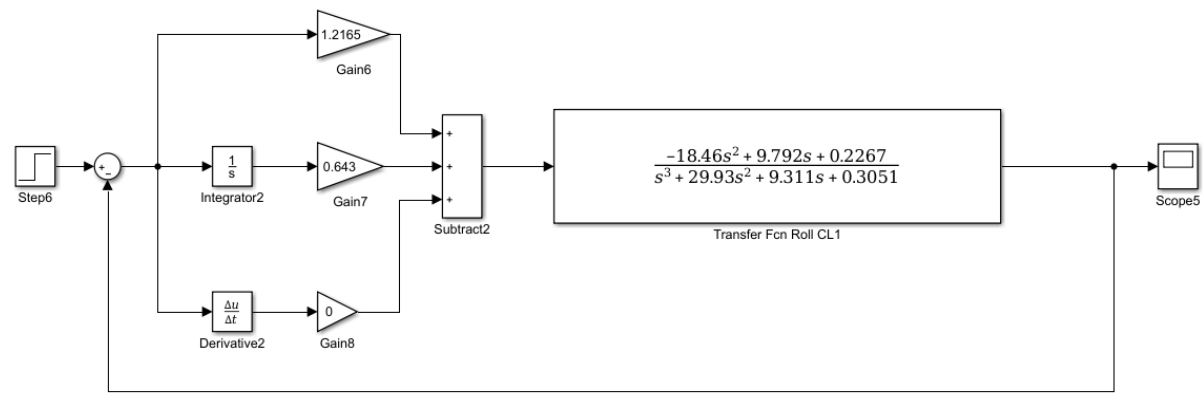

Gambar 16. Diagram Blok Pemodelan Sistem Roll

Respon sistem gerakan pitch dan roll sebelum dilakukan perancangan kontroler menunjukan nilai respon yang kurang baik karena memiliki settling time yang sangat tidak maksimal atau waktu yang dibutuhkan sistem untuk stabil disekitar nilai set point. Salah satu peran utama kontroler ialah harus dapat membuat sistem mencapai set point atau nilai yang diinginkan. Jika kehadiran kontroler tidak dapat melakukan hal tersebut maka tidak ada baiknya menggunakan kontroler. Hasil perancangan kontroler PID untuk gerakan pitch dan roll pada penelitian selanjutnya dapat dilakukan simulasi perbandingan respon sistem sebelum dan sesudah perancangan kontroler guna mengetahui sejauh mana kemampuan perancangan kontroler PID dalam mempertahankan stabilitas attitude Hexacopter. 


\section{KESIMPULAN}

Kesimpulan yang dapat ditarik dari penelitian Perancangan Sistem Pengendalian Menggunakan Kontroler PID pada Gerakan Pitch dan Roll untuk Stabilitas Attitude Hexacopter ialah :

1. Mendapatkan parameter kontroler PID untuk gerakan pitch dan roll pada hexacopter dilakukan dengan pengambilan data, pemodelan sistem dan simulasi, mencari parameter PID. Nilai parameter yang didapat untuk gerakan roll ialah Kp sebesar 1,2165 dan Ki sebesar 0,643. Nilai parameter yang didapat untuk gerakan pitch ialah Kp sebesar 1,762 dan Ki sebesar 0,933.

2. Hasil respon sistem dari kontroler PID default menunjukan nilai yang tidak optimal dan tidak dapat membuat sistem stabil untuk gerakan roll maupun gerakan pitch.

\section{DAFTAR PUSTAKA}

[1] Adi Susila Putera \& Fatwa Ramdani. 2017. "Software Testing by Standard Software Metrics Method; Study Case "Mission Planner" as UAV Ground Station Software.". e-ISSN: 22898131 Vol. 10, 1-8. Malang: Universitas Brawijaya.

[2] Artale V., C.L.R. Milazzo dan A. Ricciardello. 2013, "Mathematical Modeling of Hexacopter." Mathematical Sciences Vol. 7, 2013, no. 97, 4805 - 4811.

[3] Baldeón, J., et al. (2016), "Control for Hexacopters: A Sliding Mode Control and PID Comparison." Rev. Téc. Ing. Univ. Zulia. Vol. 39, No. 3.

[4] Kugelberg, I., (2016). Black-Box Modeling and Attitude Control of a Quadcopter in Master of Science Thesis in Electrical Engineering, Linkoping University.

[5] Ogata, K., (2010). Modern Control Engineering 5 th Edition. New Jersey: Pearson Education, Inc.

[6] Rahaja, et al. 2017. "Hovering Control of Quadrotor Based on Fuzzy Logic”. International Journal of Power Electronics and Drive System (IJPEDS). ISSN: 2088-8694. Vol. 8, No. 1. Institute of Advanced Engineering and Science.

[7] Suprapto, et al. 2017. Design and Development of Heavy-Lift Hexacopter for Heavy Payload. Direktorat Riset dan Pengabdian Masyarakat (DRPM).

[8] Tobias Magnusson. (2014). Attitude Control of a Hexarotor. Department of Electrical Engineering. Sweden: Linköpings universitet.

[9] Vanin, Matteo. (2013). Modeling, Identification and Navigation of Autonomous Air Vehicle in Tesi in Laurea Magistrale. Dipatimento di Ingegneria Dell 'Informazione. Universit'a degli Studi di Padova.

[10] Zefang, He, Long Zhao. 2014. "A Simple Attitude Control of Quadrotor Helicopter Based on Ziegler-Nichols Rules for Tuning PD Parameters". The Scientific World Journal. Beijing: Hindawi Publishing Corporation. 